\title{
ESTIMATION METHODOLOGIES FOR NATIONAL GREENHOUSE GAS EMISSION PROJECTIONS
}

\author{
Ph.D. Candidate Eng. Roxana Ivan \\ Politehnica University, Timișoara, RO-300222, România \\ roxana.nicoloiu@gmail.com
}

\section{Introduction}

There is growing scientific consensus that (i) climate change is happening, (ii) is largely human induced, and (iii) will have serious consequences for human health. The impact of climate change on global health is probably not yet large, compared with major risk factors, but will become greater later in this century [1]. Significant changes have occurred in climate over the past hundred years. Records show that mean temperature on earth rose by approximately $0.6^{\circ} \mathrm{C}$ during the 20th century. Global warming is one of those environmental issues that are most intimately, linked to socio-economic development [2]. Climate change is a long-term challenge, which can be addressed successfully only through long-term actions and international cooperation, at both regional and global levels. In order to achieve these goals, there is a huge need for analytical and forecasting tools to be applied as quickly as possible, and consistently as well, at national level. Lessons learned from these projections must help drastic methods and technologies to be developed and applied, before it will not be too late!

National framework

Romanian climate change policy objectives

A. Romania ratified the UNFCCC (United Nations Framework Convention on Climate Change) by Law 24/1994 and the Kyoto Protocol to the UNFCCC by Law 3/2001.

Also, Romania initiated and completed the process of setting new national targets for all objectives of the strategy, which was validated by the High Level Working Group on 8 June 2010 and resulted in the signing by the Romanian Government's Memorandum "Approval of values Romania's objectives for the final of Europe 2020". Agreed national objectives related to implementation of the Energy Package - climate change, congruent with the commitments of the European Commission are presented in Table 1 [3].

Factors such as climate conditions, economic growth, population, transport, industrial activities are heavily influencing the $\mathrm{CO}_{2}$ emissions values.

\begin{tabular}{ccc}
2020 Objectives & $\begin{array}{c}\text { EU 27 } \\
(\%)\end{array}$ & $\begin{array}{c}\text { National objectives } \\
(\%)\end{array}$ \\
\hline $\begin{array}{c}\text { Reducing GHG } \\
\text { (Greenhouse Gas) } \\
\text { emissions }\end{array}$ & 20 & 20 \\
$\begin{array}{c}\text { Share of energy } \\
\text { from RES in } \\
\text { gross final } \\
\text { consumption }\end{array}$ & 20 & 24 \\
$\begin{array}{c}\text { Increasing energy } \\
\text { efficiency }\end{array}$ & 20 & 19 \\
\hline
\end{tabular}

Romanian climate change policy objectives in accordance to the EU Energy- Climate Change Package [3] 


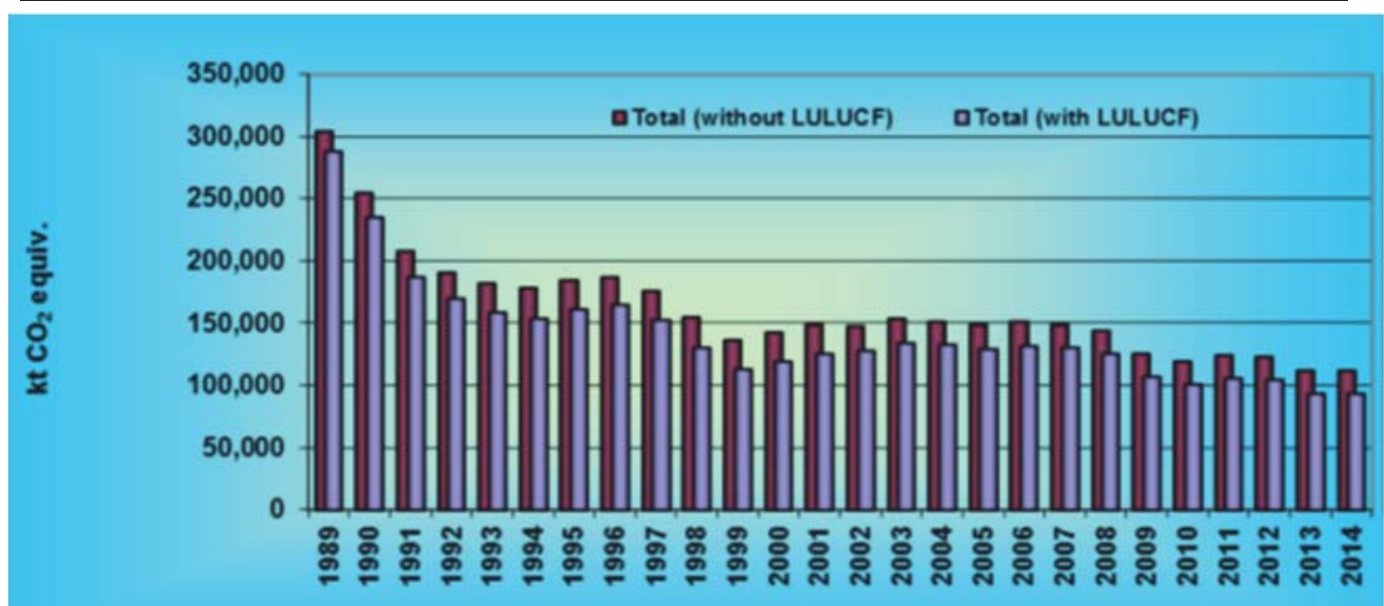

Figure 1. Trends of the national GHG emissions [4]

National greenhouse gas emission trends

$\mathrm{CO}_{2}$ emissions are contributing to global warming and account for $80 \%$ of EU greenhouse gas emissions.

According to the provisions of the Kyoto Protocol, Romania has committed itself to reduce the GHG emissions by $8 \%$ in the period 2008-2012, considering the base year (1989) levels.

As it can be deducted from the Figure 1, the emissions trend reflects the changes in this period characterized by a process of transition to a market economy. The emissions trend can be splited in the following relevant periods:

1989-1992: decline of economic activities and energy consumption

1992-1999: economy revitalization

(1997: starting of the operation of the first reactor at the Cernavoda nuclear power plant) 1999-2008: economic development

2008-2014: due to the economic crisis, the emissions have significantly decreased

According to the latest National Inventory Report submitted to UNFCCC by August 2016, the total GHG emissions decreased with $63.40 \%$ in 2014 in comparison to 1989 [4].

Estimation methodologies for greenhouse gas emission projections

In this chapter are described the most representative models for each modelling category (simulation, economic equilibrium and optimization), as well as those with the highest probability to be suitable and recommend for Romania's case study.

Models used in this evaluation are the following:
LEAP, ENPEP-BALANCE,

MERCI

MARKAL/TIMES and MESSAGE.

Simulation models

Simulation models simulate the environmental results of a selected policy option [5].

\section{Example 1: LEAP}

Long-range Energy Alternatives Planning): developed in 1980 in the USA [6]. It is a widelyused software tool for energy policy analysis and climate change mitigation assessment, it is considered both as:

bottom-up model

accounting model [5].

\section{Example 2: ENPEP}

Energy and Power Evaluation Program: was developed in 1999 by the Centre for Energy, Environmental and Economic Systems Analysis (CEEESA - Argonne National Laboratory in the USA), and the U.S. Department of Energy (DOE) [7]. It determines the response of various segments of the energy system to changes in energy prices and demand levels, being a: bottom-up model, non-linear, iterative equilibrium model [5].

Economic equilibrium models

Economic equilibrium models assess overall economic development and ecological impacts [5].

\section{Example 3: MERCI}

Model for Evaluating Regional Climate change Impacts was built up in 2009, by the Institute for Advanced Studies (IHS) Vienna. It is designed to assess different possible future developments 
in a complex economic and ecological sense, and to evaluate them with respect to the criteria important to the user, being a

top-down bottom-up hybrid model, and/or

dynamic general equilibrium model [5].

Optimization models

This optimization models identify optimal policies of identify optimal policies of climate change [5]

\section{Example 4: MARKAL}

MARKet Allocation: developed in the late 1970's by the Brookhaven National Laboratory [8]. It facilitates the analysis of different future energy system pathways over a medium to long term, by integrating energy, environmental, and economic factors, as a:

bottom-up model, or/and

dynamic partial equilibrium model [5].

\section{Example 5: MESSAGE}

The named model for Energy Supply Strategy Alternatives and their General Environmental Impact is developed in 1980's, by the International Institute for Applied Systems Analysis (IIASA) [9]. It contains technologyrich energy systems model with economic and environmental modules, defining a:

bottom-up model, and/or

systems engineering optimization tool model [5].

\section{Models evaluation}

These models serve as means to estimate costs and benefits of climate policy options, always related to a possible future development of the social, economical and environmental system, all of them being dependent on each other, to a certain extent [5]. The selection of the optimal model for climate change mitigation, for Romania, from the list of the models previously presented, raises the issue of their comparative evaluation and through them the selection of the optimum alternative. The proposed models were evaluated in a multi-criteria analysis against a number of criteria/sub-criteria that reflect: flexibility, transparency, required data intensity, limited skill requirements / user-friendliness.

Following this analysis, and based on own experience, the author demonstrates in the following and concludes that the LEAP model can be successfully used to predict the evolution of GHG emissions and to determine the environmental impact of government policies at national level.

National greenhouse gas emission projections generated by the LEAP model

LEAP is an integrated modelling tool that is used to track energy consumption, production and resource extraction in all sectors of an economy, as can be seen in Figure 2. In addition to tracking GHGs, LEAP can also be used to analyse emissions of local and regional air pollutants, making it well-suited to studies of the climate co-benefits of local air pollution reduction [6].

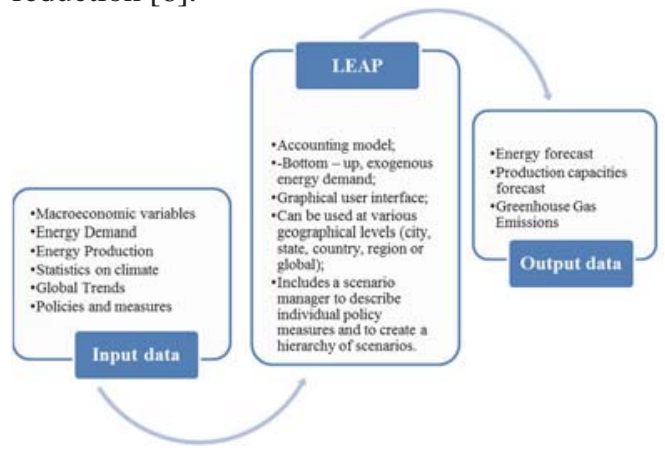

Figure 2. Input and output data of LEAP analysis model [10]

LEAP presents a complex energy analysis concepts in a transparent and intuitive way. It is flexible enough for being used by customer with a wide range of expertise, such as leading global experts who wish to design policies, and demonstrate their benefits, as well decision makers, and trainers who intend to build capacity among analysts who are learning to understand the complexity of energy systems [10]. In order to elaborate the national GHG emission projection three scenarios were, developed, by comparing their energy requirements, their social costs and benefits, and their environmental impacts, under various assumptions. These are:

The Business "As - Usual" Scenario - BAU: in this scenario the key drivers are assumed to develop based on their historical trends.

The Optimistic Scenario - OPT: this policy portfolio established mitigation targets in all sectors. It is oriented towards the principles of the EU climate change policy and adjusted according to the needs of Romania. The 
Pessimistic Scenario - PES: in this scenario the key drivers are assumed to be developed based on their historical trends towards the EU energy policy [3].

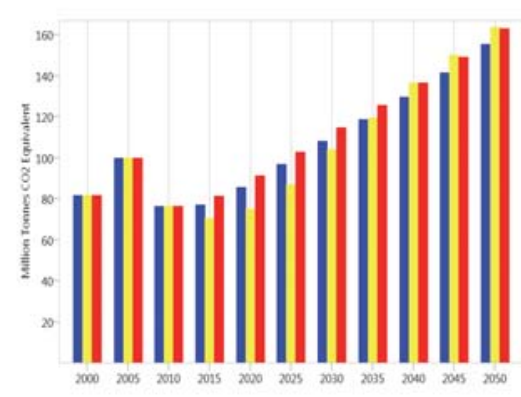

Figure 3. The evolution of the GHG emissions for the three analyzed scenarios for Romania

As it can be seen in the Figure 3, the OPT scenario continuously presented the best energy demand results - in terms of mitigation policy - followed by the PES and leaving the BAU with the highest and worse energetic request. The data are considerable large and must raise efforts in the next future, both by the stakeholders, producers and consumers, not mentioning the legislation developer and governmental agencies. This analysis was developed in order to understand and increase awareness of the impact of increasing energy demand over the amount of GHG emissions at national level and to assess effectiveness of proposed climate policies [10].

\section{Conclusions}

Climate change is a global challenge that requires a responsible approach and concrete actions at international, regional, national and local level.

This paper presents the current status of GHG national emissions in Romania, and provides an overview of the models that should be considered to be used for developing and quantifying adaptation and mitigation scenarios, for GHG projections at national level.

The author concludes that the LEAP model can be successfully used to predict the evolution of GHG emissions and to determine the environmental impact of government policies at national level.

Also, this article aims to identify various policy tools through which GHG emissions could be reduced at national level, in the perspective of the year 2050, under different scenario assumptions.

\section{Acknowledgement}

The paper was developed with the support of the University Politehnica of Timisoara, as the author is a fellow of PhD studies' program, as $\mathrm{PhD}$ candidate. She addresses warm thanks and appreciation versus the coordination of the thesis as well.

\section{References}

A. Haines, K. L. Ebi, K. R. Smith, A. Woodward: Health Risks of Climate Change: Act Now or Pay Later, The Lancet, Volume 384, No. 9948, 1073-1075, 20 September 2014 [Online]

Available:http://www.thelancet.com/pdfs/journ als/lancet/PIIS0140-6736(14)61659-7.pdf accessed 7 june 2017

K. M. Angelou: The Impact of Climate Change on Seasonal Cycles, Journal of Environmental Protection and Ecology 8, No 2, 374-379 (2007).

A. Bardici, C. Vasile, M. Pislaru, I. Voda, Dr. P. Konidari, A. Flessa M.Sc., Eleni-Danai Mavraki M.Sc: Mitigation / Adaptation scenarios and Climate Change policy portfolios for Romania Report prepared for the FP7 funded project "PROMITHEAS-4: Knowledge transfer and research needs for preparing mitigation/adaptation policy portfolios", coordinated by Prof. Dimitrios MAVRAKIS, Energy Policy and Development Centre (Greece), 2013 - [Online]

Available:http://www.promitheasnet.kepa.uoa. gr/Promitheas4/index.php/library - accessed 17 May 2017

Ministry of Environment, Water and Forests National Environmental Protection Agency Romania's Greenhouse Gas Inventory 19892014, August 2016 - [Online]

Available:http://unfccc.int/national_reports/ann ex_i_ghg_inventories/national_inventories_sub missions/items/9492.php - accessed 3 june 2017 Bernhard Felderer: Overview of Models in Use for Mitigation/Adaptation Policy, Institute of Advanced Studies (IHS), Vienna August 2011, Report prepared for the FP7 funded project "PROMITHEAS-4: Knowledge transfer and research needs for preparing 
mitigation/adaptation policy portfolios", International Institute for Applied Systems coordinated by Prof. Dimitrios MAVRAKIS, Analysis website

Energy Policy and Development Centre Available:http://www.iiasa.ac.at/web/home/res

(Greece)

LEAP website

Available:https://www.energycommunity.org/d efault.asp?action=introduction -accessed 5 june 2017 earch/researchPrograms/Energy/MESSAGE.en .html- accessed 5 june 2017

R. Ivan, O. Falup, I. Mircea, I. Ionel, Greenhouse gases emissions forecasts for different climate change policy portfolios.

Center for Energy, Environmental, and Romanian case study, Journal of Environmental Economic Systems Analysis (CEEESA), Protection and Ecology 16/ Atmospheric website pollution, No 4, 1227-1236 (2015)

Available:http://ceeesa.es.anl.gov/projects/Enp epwin.html - accessed 5 june 2017

Available:https://docs.google.com/a/jepe-

International Energy Agency - Energy journal.info/viewer? $\mathrm{a}=\mathrm{v} \& \mathrm{pid}=\mathrm{sites} \& \mathrm{srcid}=\mathrm{am}$

Technology Systems Analysis Program website Available:http://en.openei.org/wiki/MARKet_ VwZS1qb3VybmFsLmluZm98amVwZS1qb3

ALlocation_(MARKAL) - accessed 5 june VybmFsfGd4OjdhMjE4NWExNWM0NDc4M 2017 